\title{
Vessel noise effects on delphinid communication
}

\author{
F. H. Jensen ${ }^{1, *}$, L. Bejder ${ }^{2}$, M. Wahlberg ${ }^{2,3}$, N. Aguilar Soto ${ }^{4}$, M. Johnson ${ }^{5}$, \\ P. T. Madsen ${ }^{1,2,5}$ \\ ${ }^{1}$ Zoophysiology, Build. 1131, Department of Biological Sciences, University of Aarhus, 8000 Aarhus C, Denmark \\ ${ }^{2}$ Murdoch University Cetacean Research Unit, Centre for Fish and Fisheries Research, Murdoch University, \\ 6150 Western Australia, Australia \\ ${ }^{3}$ Fjord \& Bælt and University of Southern Denmark, Margrethes Plads 1, 5300 Kerteminde, Denmark \\ ${ }^{4}$ BIOECOMAC, Department of Animal Biology, La Laguna University, Tenerife, Canary Islands, Spain \\ ${ }^{5}$ Woods Hole Oceanographic Institution, Woods Hole, Massachusetts 02543, USA
}

\begin{abstract}
Increasing numbers and speeds of vessels in areas with populations of cetaceans may have the cumulative effect of reducing habitat quality by increasing the underwater noise level. Here, we first use digital acoustic tags to demonstrate that free-ranging delphinids in a coastal deepwater habitat are subjected to varying and occasionally intense levels of vessel noise. Vessel noise and sound propagation measurements from a shallow-water habitat are then used to model the potential impact of high sound levels from small vessels on delphinid communication in both shallow and deep habitats, with bottlenose dolphins Tursiops sp. and short-finned pilot whales Globicephala macrorhynchus as model organisms. We find that small vessels travelling at 5 knots in shallow water can reduce the communication range of bottlenose dolphins within $50 \mathrm{~m}$ by $26 \%$. Pilot whales in a quieter deep-water habitat could suffer a reduction in their communication range of $58 \%$ caused by a vessel at similar range and speed. Increased cavitation noise at higher speeds drastically increases the impact on the communication range. Gear shifts generate high-level transient sounds (peakpeak source levels of up to $200 \mathrm{~dB}$ re $1 \mu \mathrm{Pa}$ ) that may be audible over many kilometres and may disturb close-range animals. We conclude that noise from small vessels can significantly mask acoustically mediated communication in delphinids and contribute to the documented negative impacts on animal fitness.
\end{abstract}

KEY WORDS: Acoustic communication · Vessel noise $\cdot$ Masking $\cdot$ Bottlenose dolphins $\cdot$ Pilot whales Recreational vessels $\cdot$ Whale watching

Resale or republication not permitted without written consent of the publisher

\section{INTRODUCTION}

Marine organisms are exposed to an array of human pollutants, including increasing levels of anthropogenic noise (Nowacek et al. 2007, Weilgart 2007, Tyack 2008). Most marine vertebrates exploit the low absorption of sound underwater to acquire information about their environment and to communicate (Tyack \& Miller 2002, Popper 2003, Montgomery et al. 2006). Cetaceans, in particular, have evolved auditory and sound production systems that allow them to use sound for a series of vital processes, including communication, navigation and detection of predators or prey (Au 1993). This makes cetaceans susceptible to the nega- tive effects of man-made noise if the exposures cause behavioural or physical changes or impede the process of conveying or acquiring information acoustically (Richardson et al. 1995).

The most widespread source of anthropogenic underwater noise is that of motorized vessels, which includes shipping and increasing numbers of recreational and whale-watching boats (NRC 1994, 2003, McCarthy 2004). Vessels generate underwater noise from mechanical vibrations of the engine or hull, but most of the medium- and high-frequency components of vessel noise stem from cavitation, a phenomenon whereby air bubbles form and collapse on the edge of fast-moving propeller blades (Ross 1976). The level of 
cavitation noise increases with the speed of the propeller and therefore also with the speed of the vessel (Arveson \& Vendittis 2000). Since cavitation noise is very broadband, it overlaps with the frequency range of many cetacean sounds (e.g. Aguilar Soto et al. 2006). Given that detection of an acoustic signal is ultimately limited by the ambient noise levels in the same frequency band as the signal, introducing broadband anthropogenic noise into the environment will decrease the chance of detecting a signal and thus mask the signal for the receiver (Gelfand 2004). If features within the signal convey information, it may be important to receive the full signal with an adequate signalto-noise ratio to recognize the signal and resolve the essential features (Brumm \& Slabbekoorn 2005). As ambient noise or transmission range increases, information will be lost at the receiver, ranging from subtle features to complete failure to detect the signal (Gelfand 2004). Consequently, the active space in which animals are able to detect the signal of a conspecific (Marten \& Marler 1977) will decrease with increased masking noise.

In many coastal areas, motorized vessels used for various purposes may constitute an important source of disturbance for cetacean populations. As motorized vessels become faster and more widespread, they contribute significantly to the ambient noise level at the communication frequencies used by many marine animals (Haviland-Howell et al. 2007). Given the high and increasing number of vessels in many habitats of importance for marine mammals (McCarthy 2004), there is a pressing need to study the impact of boating activity on cetaceans and to quantify the mechanisms behind these impacts (NRC 2005).

Whale-watching vessels constitute a particular type of vessel traffic that deserves special mention because these vessels actively approach and congregate around specific cetacean populations. Whale-watching is a growing industry with significant socioeconomic implications for coastal communities in $>119$ countries (O'Connor et al. 2009). Even though whale-watching has often been termed benign (Hoyt 1993), attention has recently focused on the potential disturbance of cetaceans targeted by this industry. Varying degrees of behavioural changes in cetaceans linked to vessel activities have been shown in short-term studies (Richardson et al. 1995, Nowacek et al. 2001, Bejder \& Samuels 2003), and the effects of noise from whalewatching vessels have been addressed ( $\mathrm{Au} \&$ Green 2000, Erbe 2002, Buckstaff 2004). However, interpretation of vessel impacts around cetaceans is often confounded by complex behavioural patterns, lack of baseline data, correlations between fitness and the ability to react (Stillman \& Goss-Custard 2002, Beale \& Monaghan 2004), prior displacement of the most sensi- tive individuals (Bejder et al. 2006a), and even by biases introduced by the observation platform itself (Bejder \& Samuels 2003). A recent study has linked long-term declines in dolphin abundance to an increase in vessel activity (Bejder 2005, Bejder et al. 2006b). The study demonstrated that interpretation of short-term studies may lead to erroneous conclusions about the actual impact on cetaceans (Bejder 2005, Bejder et al. 2006b). The International Whaling Commission (IWC) has recently stated that ' $[t]$ here is compelling evidence that the fitness of individual odontocetes repeatedly exposed to whale-watching vessel traffic can be compromised and that this can lead to population level effects' (IWC 2006, p. 47).

In the present study, we investigate under what circumstances the noise levels generated by small vessels are sufficient to mask delphinid communication signals. We show that wild cetaceans are routinely exposed to high noise levels from nearby vessels in the frequency bands used for communication. We quantify the source levels produced by 2 small vessels representative of vessels used in recreation, research and small-scale whale-watching, and estimate their potential to impact acoustic communication in 2 common delphinid species.

\section{MATERIALS AND METHODS}

Vessel noise experienced by free-ranging shortfinned pilot whales. We deployed digital acoustic recording tags (DTAGs; Johnson \& Tyack 2003) on short-finned pilot whales Globicephala macrorhynchus (pilot whales hereafter) off the coast of Tenerife, Canary Islands, Spain, during 2003 and 2005. The tags sampled 16 bit audio at $96 \mathrm{kHz}$ (2003) or $192 \mathrm{kHz}$ (2005). Several sequences of elevated noise levels from vessels in the vicinity of tagged whales were identified. To document the variability of noise levels experienced by free-ranging pilot whales, we quantified the noise level of 2 sequences of background noise and 6 sequences of vessel noise in which the tagged whale moved little and consequently produced little flow noise. A $50 \mathrm{~s}$ window from each sequence, centred on the point of highest noise intensity, was filtered (2 to $12.5 \mathrm{kHz}, 4$-pole Butterworth filter) and analysed in $1 \mathrm{~s}$ blocks for RMS (root mean square) noise level in communication frequencies.

Background noise. We measured background noise levels in 2 different habitats. Koombana Bay, Bunbury, Western Australia ( $33^{\circ} 17^{\prime} \mathrm{S}, 115^{\circ} 39^{\prime} \mathrm{E}$ ) was chosen as representative of a shallow-water habitat close to shore. The bay is close to a busy port and is often frequented by recreational boats. Snapping shrimp contribute significantly to the underwater noise levels in a 
broad frequency band in this habitat. A coastal bottlenose dolphin population (Tursiops sp.) resides in and around the bay, and a single dolphin-watching company operates a daily tour. We suspended a calibrated B\&K 8101 hydrophone with preamplifier (-184 dB re $1 \mathrm{~V} \mathrm{\mu Pa}^{-1}$ sensitivity) in mid-water (3 $\mathrm{m}$ depth), $50 \mathrm{~m}$ from the recording vessel in Sea State 0 (glassy sea surface). The hydrophone was connected through a custom-built, low-noise amplification and filtering box (40 dB gain, bandpass filter: $10 \mathrm{~Hz}$ to $50 \mathrm{kHz}$ ) to an M-Audio Microtrack 24/96 compact-flash recorder (calibrated peak clip level of $148 \mathrm{~dB}$ re $1 \mu \mathrm{Pa}$ ), which digitized and stored data in $96 \mathrm{kHz} / 16$ bit WAV-format files for later processing. Background noise measurements were made when no boats were observed visually 5 min before and after each recording, and when no cetaceans were detected either visually or acoustically during the recordings.

An area off the SW coast of Tenerife in the Canary Islands was chosen as representative of a deep-water habitat. The water depth here falls rapidly to several 100s of metres close to the shore. Recordings of ambient noise were made at 2 to $4 \mathrm{~km}$ from the coast and at a water depth of $>1 \mathrm{~km}$. A population of bottlenose dolphins and $>300$ short-finned pilot whales residing in this area (Heimlich-Boran \& Heimlich-Boran 1990, Heimlich-Boran 1993) are the subjects of a substantial boat-based whale-watching industry. We used a calibrated Reson TC4032 hydrophone with preamplifier

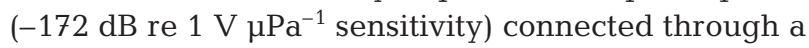
filter and amplifier (40 dB gain, bandpass filter: $100 \mathrm{~Hz}$ to $40 \mathrm{kHz}$ ) to a digital audio tape recorder (Sony DAT) sampling at $48 \mathrm{kHz}$ (calibrated peak clip level of $137 \mathrm{~dB}$ re $1 \mu \mathrm{Pa}$ ). The hydrophone was lowered from the recording platform to a depth of $3 \mathrm{~m}$ at Sea State 0. Again, no other vessels or cetaceans were detected visually or acoustically within several minutes of any background noise recordings.

All data analyses were performed with customwritten Matlab 6.5 scripts. One minute of background noise for both habitats was divided into 60 nonoverlapping $1 \mathrm{~s}$ chunks and used to quantify the background noise and the variation resulting from using short (1 s) chunks for analysis.

Vessel noise and transmission measurements. Measurements of vessel noise were done in Koombana Bay from 10 to 16 February 2007. Sound recordings were made during early morning until noon with a Sea State $<2$ (smooth sea surface). All measurements were conducted approximately $270 \mathrm{~m}$ parallel to the coast in 5 to $7 \mathrm{~m}$ water. The bottom sloped evenly from the shore and consisted of sand with occasional sea grass patches.

We investigated 2 small boats representative of vessels involved in recreational boating, research activities and small-scale whale-watching. The first vessel (hereafter termed '2-stroke') was a $6.0 \mathrm{~m}$ aluminiumhulled vessel equipped with a Mercury 2-stroke, 135-horsepower outboard engine. The second vessel (hereafter termed '4-stroke') was a $5.0 \mathrm{~m}$ Quintrex aluminium-hulled vessel propelled by an outboard Yamaha 4-stroke, 80-horsepower outboard engine.

Underwater ambient noise levels (the sum of vessel noise and background noise) were recorded from in front of the source (vessel approaching the recording platform) and from the side of the source (vessel circling the recording platform). Each boat was recorded at 3 speeds (2.5, 5 and 10 knots) and at 5 distances from the recording platform $(10,30,50,100$ and $200 \mathrm{~m})$. Marker buoys were moored for range estimation during vessel approaches, and distance was confirmed by measurements with a laser rangefinder. For measurements of vessel noise, we suspended a linear array of 3 calibrated B\&K 8101 hydrophones $(0.5,3$ and $5.5 \mathrm{~m}$ depths) from a buoy off the side of the recording vessel. The hydrophones were connected through custom-built, low-noise amplification and filtering boxes (variable gain, bandpass filter: $10 \mathrm{~Hz}$ to $50 \mathrm{kHz}$ ) to a 4-channel, 16-bit Wavebook sampling at $150 \mathrm{kHz}$. The recording chain had a flat frequency response $( \pm 2 \mathrm{~dB})$ from $10 \mathrm{~Hz}$ up to $48 \mathrm{kHz}$ and peak clip levels of 145 to $166 \mathrm{~dB}$ re $1 \mu \mathrm{Pa}$, depending on amplification settings and hydrophone. At the end of each day, we recorded platform noise with no vessels close to the recording platform to control for slight changes in background levels from day to day.

To estimate transmission loss and back-calculated source levels (SL) for continuous vessel noise, we fitted the broadband $(0.2$ to $40 \mathrm{kHz}, 4$-pole Butterworth filter) received RMS sound pressure level from the 2 vessels approaching or circling at 10 knots to a geometric spreading loss model, SL $-k \times \log$ (range), to estimate $k$. Frequency-dependent absorption was ignored for the low frequencies and short ranges considered here (Urick 1983). Only recordings at 10 knots were used for the transmission loss estimates to ensure a good signalto-noise ratio at all ranges. Source levels at speeds of 5 knots were calculated from received levels at $10 \mathrm{~m}$ distance and corrected for the derived transmission loss. Source levels were not estimated for 2.5 knots due to low signal-to-noise ratio at this speed.

Recordings were analysed in $1 \mathrm{~s}$ windows centred at the time when the vessel passed each of the marker buoys. Selections were checked for interfering Tursiops sp. vocalizations, and noise levels were quantified as broadband RMS sound pressure (0.2 to $48 \mathrm{kHz}$ ) and RMS sound pressure over the vocalization frequency range (2 to $12.5 \mathrm{kHz}, 4$-pole Butterworth filter) encompassing the frequency band of both model species. Finally, we filtered $(0.2$ to $48 \mathrm{kHz}, 4$-pole Butterworth filter) and quantified transient sounds from gear 
shifts of vessels at each range by their peak-to-peak pressures $\left(\mathrm{dB}\right.$ re $\left.1 \mu \mathrm{Pa}_{\mathrm{pp}}\right)$ and sound exposure levels $\left(\mathrm{dB}\right.$ re $1 \mu \mathrm{Pa}^{2} \mathrm{~s}^{-1}$ ) and back-calculated these to source levels assuming spherical spreading for these transient sounds (Urick 1983, Madsen et al. 2006).

Impact assessment. Auditory masking occurs when the perception of one sound is affected by the presence of another sound within the same auditory filter band (Gelfand 2004). The mammalian auditory system is usually approximated by a bank of one-third octave filter bands (Fay 1988). Filters with constant fractional bandwidth are also used for toothed whales to model the extent to which detection of pure tones will be masked by noise, with $1 / 12$ octave (Erbe 2002) to onethird octave filter bands (Richardson et al. 1995, Madsen et al. 2006) being applied depending on frequency range. For all species where it has been investigated, the critical bandwidth remains constant over a fairly wide range of noise levels so that a $10 \mathrm{~dB}$ increase in noise level will result in a $10 \mathrm{~dB}$ increase in the detection threshold of the signal (Lohr et al. 2003). In order to make the present results comparable with the main body of existing studies, we approximated the delphinid auditory system as a bank of one-third octave filters for communication frequencies. The RMS sound pressure in each one-third octave band is termed the one-third octave level (TOL). For frequencies $>2 \mathrm{kHz}$, the detection thresholds reported for Tursiops spp. (Johnson 1967) are all lower than background TOLs in both habitats, meaning that detection of whistles in bottlenose dolphins will be limited by ambient noise rather than by the absolute hearing threshold. This was also assumed for pilot whales since no audiograms have been reported for this species.

In bottlenose dolphins, the fundamental whistle contours seem to convey information between the animals (Janik et al. 2006). Bottlenose dolphins use whistles modulated between 4 and $20 \mathrm{kHz}$ (Caldwell \& Caldwell 1969, Janik \& Slater 1998), but fundamentals $>10 \mathrm{kHz}$ were only rarely observed in Koombana Bay (F. H. Jensen et al. unpubl. data). Consequently, we included 5 one-third octave bands with centroid frequencies from 4 to $10 \mathrm{kHz}$ to estimate the potential masking impacts on bottlenose dolphin communication. Fundamental frequencies of short-finned pilot whale tonal sounds are reported to be between 2 and $14 \mathrm{kHz}$ (Caldwell \& Caldwell 1969) or between 6 and $11 \mathrm{kHz}$ (Rendell et al. 1999). However, tagged pilot whales residing around Tenerife regularly use tonal sounds as low as $2 \mathrm{kHz}$ (F. H. Jensen et al. unpubl. data), and we therefore chose to model masking effects on pilot whale communication over 9 one-third octave bands with centroid frequencies from 2 to $12.5 \mathrm{kHz}$. Frequency bands analysed for the 2 species are depicted in Fig. 2.
For both species, we assumed that: (1) the whistle is modulated over the full frequency span and detection of signal elements in all one-third octave bands is ultimately limited by noise; (2) source level and fundamental frequency do not change in response to a higher background noise level; $(3)$ the animals have a low receiving directionality at whistling frequencies (Au \& Moore 1984); and (4) the communication sounds attenuate spherically according to $20 \log$ (range) transmission loss.

Following Madsen et al. (2006), we considered an increase in the ambient TOL of $>3 \mathrm{~dB}$ as being capable of significantly masking a narrowband signal. This threshold is reached when the sound intensity generated by a passing vessel equals or exceeds the sound intensity of the background noise so that the total power of the 2 noise components (expressed in decibels) would be at least $3 \mathrm{~dB}$ greater than the background noise component alone. For any receiver, a minimum signal-to-noise ratio (SNR) is necessary for the detection and processing of a signal. An increase in ambient noise means that the receiver has to be closer to the source to maintain the same SNR and the active space will consequently be smaller. Even when the source level and absolute range of a communication signal is unknown, the relative effect on range due to an increase in in-band ambient noise can be estimated (Møhl 1981, Aguilar Soto et al. 2006). For a narrowband signal processed by one-third octave filters, we calculated how much closer a receiver would need to be in order to maintain the same SNR using Eqs. (1) \& (2):

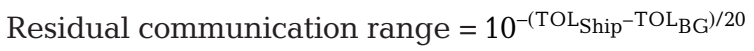

Communication range reduction $=$

$$
1-\left(10^{-\left(\mathrm{TOL}_{\mathrm{Ship}}-\mathrm{TOL}_{\mathrm{BG}}\right) / 20}\right)
$$

where $\mathrm{TOL}_{\text {Ship }}$ and $\mathrm{TOL}_{\mathrm{BG}}\left(\mathrm{dB}\right.$ re $\left.1 \mu \mathrm{Pa}_{(\mathrm{RMS})}\right)$ are the RMS sound pressures for ship noise and background noise, respectively, measured in one-third octave bands of the signal.

Since the signals of the 2 model species may be modulated over a range of species-specific frequencies, we used 3 different statistics of the recorded vessel noise as proxies to quantify the potential for masking whistles. Measure A: The largest noise level increase in any of the species-specific TOLs.

Measure B: The increase in broadband noise over the full frequency range of the whistle.

Measure C: The smallest noise level increase in any of the species-specific TOLs.

The 3 measures quantify a range of potential masking effects that may apply to communication sounds: Measure A is an upper boundary estimate of the effect of noise on signalling range. It implies that all the fre- 
quency components of the whistle are necessary for decoding the signal and that the range of the signal is therefore limited by the frequency band most affected by masking. Measure B considers the broadband increase in masking noise over the full whistle frequency band and so does not take into account narrowband processing in the receiver. This measure is relevant if the receiver operates as a band-limited energy detector. Measure $\mathrm{C}$ will result in the least quantifiable effect on signal range and provides a lower boundary on masking impact. It implies that the signal would still be detected if all but the TOL was masked and the range would therefore be determined by the frequency band least affected by noise. This might be the case if the simple detection of the whistle is sufficient (i.e. if the frequency variation of the whistle does not carry important information).

\section{RESULTS}

\section{Vessel noise experienced by free-ranging pilot whales}

Several sequences of elevated noise levels due to nearby vessels were identified in tag data recorded on pilot whales Globicephala macrorhynchus in Tenerife. The waveform and spectrogram of a short example sequence is shown in Fig. 1. The spectrum of this sequence was broadband with noise energy extending beyond $45 \mathrm{kHz}$ (Fig. 1b), which was likely caused by cavitating propellers. Within this short exposure, noise levels increased by $>20 \mathrm{~dB}$ within the frequencies that pilot whales normally use for whistle communication, but gradually decline to background noise levels again (Fig. 1c). Other vessel noise extracts (50 s of each sequence are plotted to compare their noise level with the shorter sequence) demonstrate a great temporal variability in the noise to which free-ranging cetaceans are subjected. The highest in-band received levels measured constitute an elevation of up to $55 \mathrm{~dB}$ above background noise within communication frequencies (Fig. 1c), an increase in noise level that was likely caused by the local high-speed ferry.

\section{Background noise}

Background noise levels at frequencies $>1 \mathrm{kHz}$ were found to be considerably higher in the shallow habitat of Koombana Bay than in the deep-water habitat close to Tenerife (Fig. 2). For frequencies $>2 \mathrm{kHz}$, TOLs derived from $1 \mathrm{~s}$ chunks in both habitats varied by less than $\pm 2 \mathrm{~dB}$ (95\% confidence interval). Consequently, masking impacts calculated from TOLs of $1 \mathrm{~s}$ noise

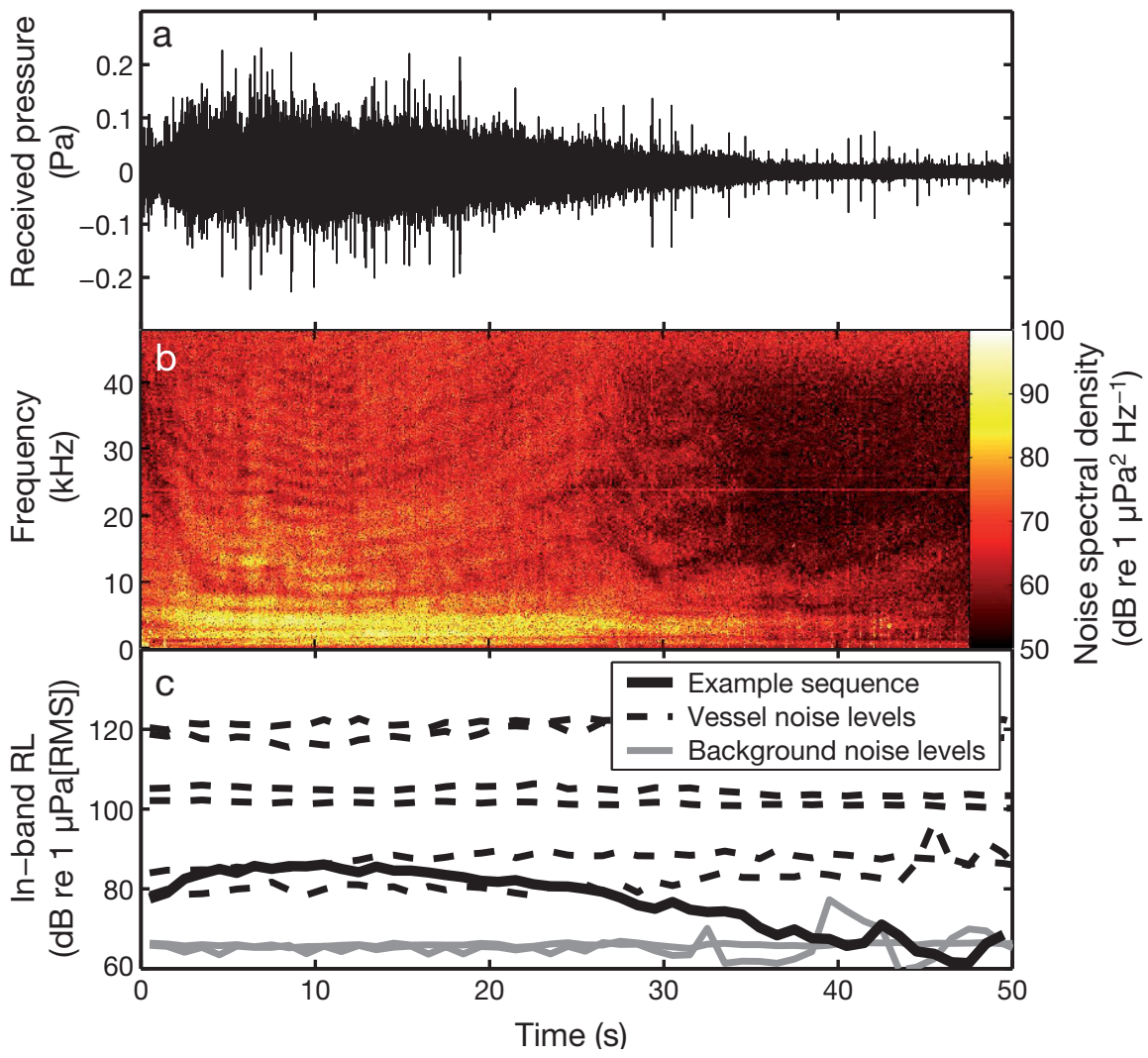

Fig. 1. Noise exposure. Examples of how short-finned pilot whales Globicephala macrorhynchus with digital acoustic tags off the coast of Tenerife are exposed to varying degrees of vessel noise. (a) Exemplary sequence of short-duration (50 s) exposure to a passing vessel, showing the received pressure variation during a single exposure. (b) Spectrogram (sample rate: $192 \mathrm{kHz}$; fast Fourier transform [FFT] size: 8192 samples; $50 \%$ overlap) showing the broad frequency range covered during the brief exposure. Levels are given in average noise spectral density ( $\mathrm{dB}$ re $1 \mu^{2} \mathrm{~Pa}^{2} \mathrm{~Hz}^{-1}$ ). (c) RMS (root mean square) received level (RL) within the frequency band of pilot whale whistles (filtered using a 4 -pole, 2 to $12.5 \mathrm{kHz}$ Butterworth filter) and calculated for $1 \mathrm{~s}$ blocks throughout the $50 \mathrm{~s}$ exposure period of the example sequence (black line). Short $50 \mathrm{~s}$ extracts of longer-term (>5 min total duration) noise exposures show the variation in exposure levels that the whales may be subjected to (broken lines) compared to the lower levels of background noise (grey lines) 


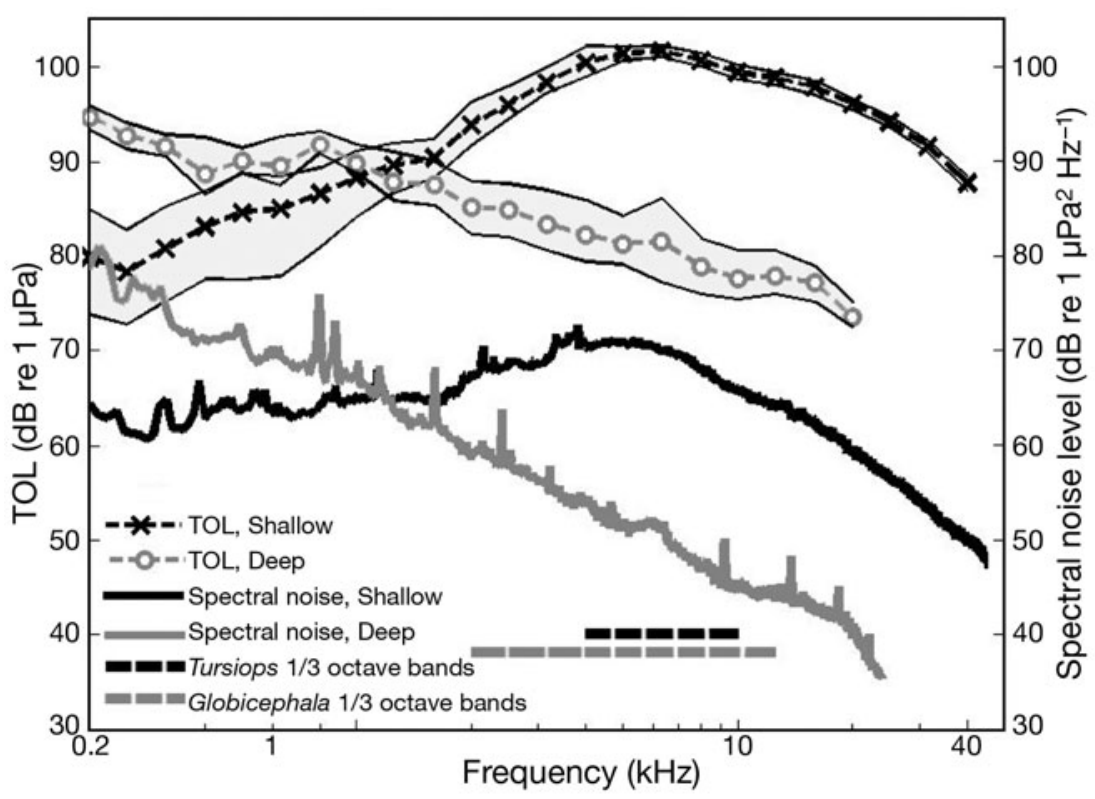

Fig. 2. Background noise in 2 different habitats: the shallow-water habitat in Koombana Bay is shown as spectral noise density (black solid line) and onethird octave level (TOL) (mean and 95\% confidence levels; black line with crosses). Background noise levels in the deep-water area off Tenerife are also shown as spectral noise density (grey line) and TOL (mean and 95\% confidence levels; grey line with circles). Black and grey broken lines depict the one-third octave frequency bands taken as representative for bottlenose dolphin Tursiops sp. and pilot whale Globicephala macrorhynchus whistle communication in the present study

samples will also have a $\pm 2 \mathrm{~dB}$ uncertainty. This was taken into account during subsequent impact assessment by limiting significant impacts to those caused by a TOL increase of $>3 \mathrm{~dB}$.

\section{Transmission loss}

Transmission loss of continuous vessel noise in Koombana Bay followed an almost cylindrical spreading model (log-linear regression: $12.8 \mathrm{~dB}$ per decade, $95 \%$ confidence interval: 10.8/13.5, df = 18) as expected for long-duration sounds propagating in a shallow-water habitat (Urick 1983, Miksis-Olds \&

Table 1. Back-calculated root mean square (RMS) source levels (SL; means \pm $\mathrm{SD})$ quantified as broadband energy ( 0.2 to $40 \mathrm{kHz}$ ) and energy in the frequency band of pilot whale Globicephala macrorhynchus whistles (2 to $12.5 \mathrm{kHz}$ )

\begin{tabular}{|lcc|}
\hline Vessel, speed & $\begin{array}{c}\text { SL }(0.2-40 \mathrm{kHz}) \\
\mathrm{dB} \text { re } 1 \mu \mathrm{Pa}_{\mathrm{RMS}} \text { at } 1 \mathrm{~m}\end{array}$ & $\begin{array}{c}\text { SL }(2-12.5 \mathrm{kHz}) \\
\mathrm{dB} \text { re } 1 \mu \mathrm{Pa}_{\mathrm{RMS}} \text { at } 1 \mathrm{~m}\end{array}$ \\
\hline 2-stroke, 5 knots & $139 \pm 1.0$ & $132 \pm 3.0$ \\
4-stroke, 5 knots & $138 \pm 2.6$ & $134 \pm 2.2$ \\
2-stroke, 10 knots & $149 \pm 0.6$ & $146 \pm 0.6$ \\
4-stroke, 10 knots & $152 \pm 0.3$ & $144 \pm 0.5$ \\
\hline
\end{tabular}

Miller 2006). Transmission loss in the deep-water habitat off Tenerife was assumed to be spherical as the depth here was much greater than the modelled distances.

\section{Vessel noise}

The broadband ( 0.2 to $40 \mathrm{kHz}$ ) backcalculated source level (Table 1) and TOLs (Fig. 3) for approaching vessels depended primarily on speed. At speeds of 2.5 knots, measured noise levels in some one-third octave bands were comparable to the background noise levels (Fig. 3), and source levels were not estimated for these speeds.

Received vessel noise in the frequency band between 2 and $12.5 \mathrm{kHz}$ was only slightly influenced by the orientation or type of the boat or the depth of receivers. Noise levels were significantly higher when the receiver was to the side of the circling source vessel than when it was in front of the approaching vessel (Wilcoxon signedrank test, $N=12, T=39, \mathrm{p}=0.0005)$, but the mean difference in level was only $3 \mathrm{~dB}$. There was a tendency for the 2-stroke engine to emit more noise in the whistle frequency band than the 4-stroke engine (Wilcoxon signed-rank test, $N=12, T=$ $25, \mathrm{p}=0.0503$, mean difference $=1.4 \mathrm{~dB}$ ). Noise levels on the top hydrophone were slightly lower than on the middle and bottom hydrophone, with mean differences of 1.2 and $1.3 \mathrm{~dB}$, respectively.

\section{Impact assessment}

Given the strong similarity across vessel type and orientation, we averaged the impact assessments for the 2 vessels to give a simpler and more general representation of the data. The ranges of quantifiable masking impacts are shown for both bottlenose dolphins Tursiops sp. in a shallow area (Fig. 4a) and pilot whales Globicephala macrorhynchus in a deep-water area (Fig. 4b). In the shallow-water habitat, the broadband impact measure (Measure B) indicated that vessels moving at $<2.5$ knots did not significantly increase ambient noise levels within bottlenose dolphin frequen- 
Fig. 3. Vessel noise at different speeds shown as received one-third octave levels (TOL) bands recorded at a distance of $10 \mathrm{~m}$ from the 2 circling vessels, powered by either a (a) 2-stroke or (b) 4-stroke engine. Platform noise levels from the recording site (taken with the array from the recording vessel and without other vessels nearby) and background noise levels (recorded with a hydrophone suspended $50 \mathrm{~m}$ from the recording platform) from Koombana Bay (shallow area) have been superimposed over both figures. Shaded areas represent the frequency ranges used for estimating masking impact on pilot whale Globicephala macrorhynchus (dark shading, 2 to $12.5 \mathrm{kHz}$ ) and bottlenose dolphin Tursiops sp. (light shading, 4 to $10 \mathrm{kHz}$ ) tonal sounds

cies. In contrast, cavitation noise from faster-moving vessels resulted in a substantial increase in the ambient noise at ranges even beyond $50 \mathrm{~m}$.

To apply the measurements of vessel noise recorded in shallow water to the assessment of impact in a deep-water habitat, we corrected for the different transmission losses in the 2 habitats. This was done by subtracting the difference between the measured transmission loss in the shallow-water habitat, i.e. $12.8 \log$ (range), and the assumed spherical spreading in the deep-water habitat 20 log(range), from the measured TOLs in Koombana Bay. The lower background noise levels and the use of different whistle frequencies meant that the impacts on the communication range were generally more severe for nearby pilot whales in the deep-water habitat, but also declined faster with increased distance due to the higher spreading loss (Fig. 4). When vessel noise was low, so that the measured TOLs were close to platform TOLs, it would be difficult to reliably quantify the actual contribution of the vessel to the measured noise levels. As a conservative estimate of each measurement in which TOLs were within $3 \mathrm{~dB}$ of platform noise levels, we defined the lower impact boundary (Measure C) to
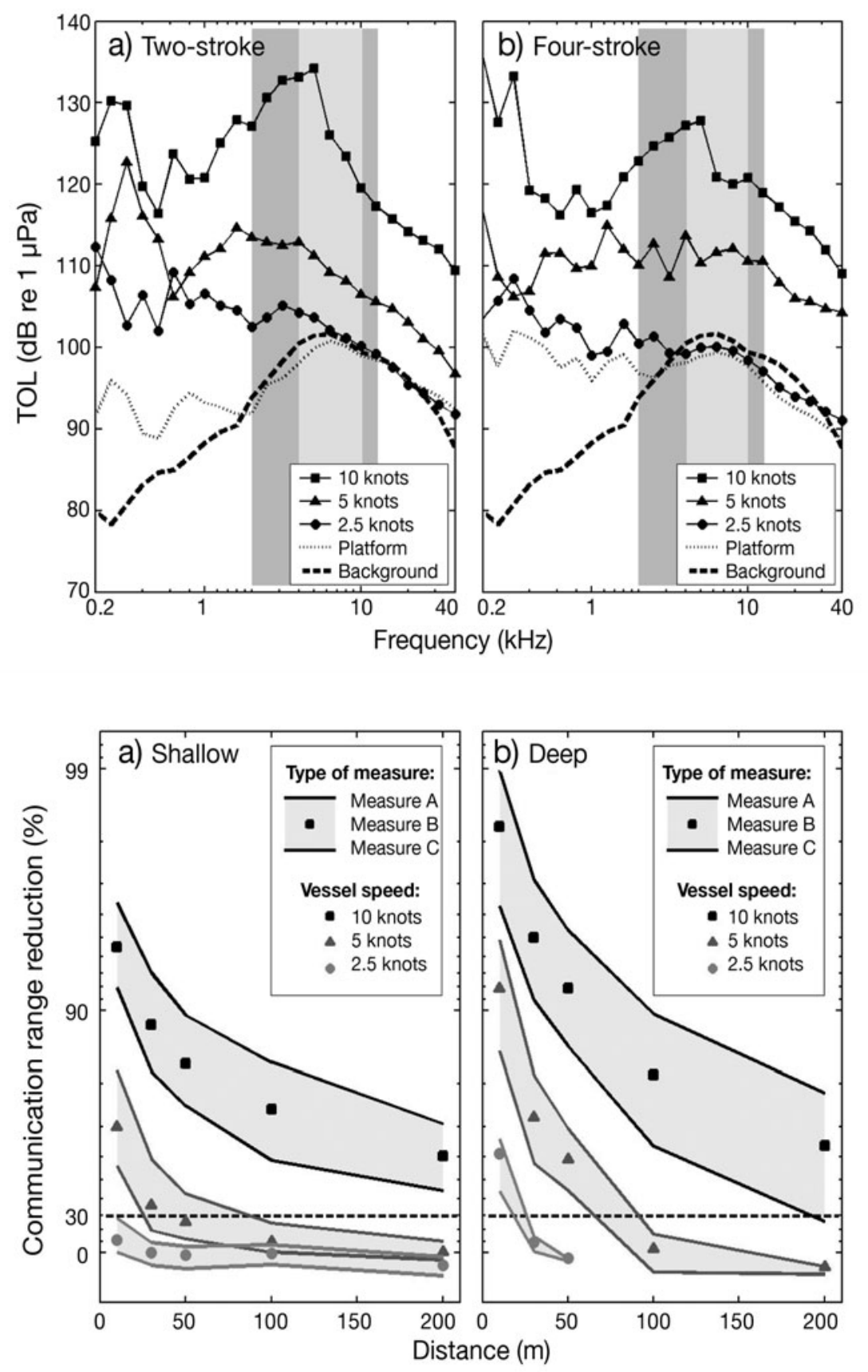

Fig. 4. Masking impact for the 2 model species (Tursiops sp. and Globicephala macrorhyncus) in their respective habitats as a function of distance between vessel and delphinid. (a) Bottlenose dolphins in a shallow-water habitat; transmission loss (TL) $=12.8$ log(range). (b) Pilot whales in a deep-water habitat; TL = $20 \log$ (range). Data from the 2 vessels and movement patterns have been averaged for each range/speed combination and are given as the relative reduction in communication range at a given distance from the vessel compared to a situation with only background noise. Three measures based on loss of signal-tonoise ratios (SNR) are depicted: for each speed versus distance plot (shaded area), the upper line (Measure A) reflects the largest measure of impact from masking (greatest SNR loss in the one-third octave bands used by the delphinid), the markers (Measure B) reflect the typical broadband measure (SNR loss across entire frequency range), and the lower line (Measure C) reflects a detection-based measure of impact (least SNR loss in the TOLs used by the delphinid). Masking of $<3 \mathrm{~dB}$ (dashed black line) is not considered significant 
be $0 \%$ effect on communication range and calculated the broadband impact (Measure B) and upper impact boundary (Measure A) from the remaining one-third octave bands in which noise levels exceeded platform noise levels by $>3 \mathrm{~dB}$. Because some TOLs from vessels moving 2.5 knots were close to background noise TOLs of the shallow recording habitat, we could not document significant masking for an average small vessel moving 2.5 knots at any distance tested.

\section{Gear shifts}

Gear shifts were found to produce broadband and relatively high-level transients with a reverberant structure. Received peak-peak levels at $50 \mathrm{~m}$ reached $164 \mathrm{~dB}$ re $1 \mu \mathrm{Pa}_{\mathrm{pp}}$ with sound exposure levels (SEL) of $126 \mathrm{~dB}$ re $1 \mu^{2} \mathrm{~Pa}^{2}$ s (Fig. 5). Mean back-calculated source levels for all ranges were $189 \mathrm{~dB}$ (range: 173 to $198 \mathrm{~dB}$ ) re $1 \mu \mathrm{Pa}_{\mathrm{pp}}$, with a mean back-calculated SEL of $141 \mathrm{~dB}$ (range: 130 to $149 \mathrm{~dB}$ ) re $1 \mu \mathrm{Pa}^{2} \mathrm{~s}$.

\section{DISCUSSION}

The last half a century has registered a steady rise in ocean noise levels due to increases in the number of vessels and in their propulsion power (Ross 1976, Urick 1983). Acoustic pollution is considered one of the factors affecting habitat quality in the oceans (NRC 2003, Tyack 2008). Low-frequency vessel noise overlaps with the vocalizations of baleen whales and many species of fish and pinnipeds (Richardson et al. 1995, NRC 2003, Tyack 2008). The increasing dominance of faster vessels (McCarthy 2004, Southall 2005) has raised cavitation noise at medium and high frequencies, overlapping with the acoustic signals of a wider range of marine fauna such as toothed whales (Arveson \& Vendittis 2000, Aguilar Soto et al. 2006). This has, in turn, raised concern that vessel noise might impact cetaceans by masking sounds used for acoustic communication or prey detection (Richardson et al. 1995).

Auditory masking of communication signals is only one of many possible consequences of increased vessel presence, but may nevertheless be critical for many delphinids that rely on acoustic communication. The bottlenose dolphin Tursiops sp. is an example of a cetacean that lives in fission-fusion societies (Wursig \& Wursig 1977, Connor et al. 2000, Connor et al. 2006), where acoustic cues play an important role in mediating social structure (Janik \& Slater 1998, Watwood et al. 2005), predator avoidance (Deecke et al. 2005), mate choice (Gerhardt \& Klump 1988), mothercalf interactions (Renouf 1984, Smolker et al. 1993), cooperative foraging (Janik 2000) and perhaps cultural learning or eavesdropping (Janik 2005). Sound most likely serves similar functions for the highly social short-finned pilot whale Globicephala macrorhynchus (Heimlich-Boran \& Heimlich-Boran 1992, Heimlich-Boran 1993). Pilot whales perform deep dives and have a rich vocal repertoire that, among other functions, may facilitate group cohesion by enabling diving animals to rejoin the group at the surface (Aguilar Soto 2006). For both of these highly vocal delphinid species, prolonged periods of masking noise may interfere with acoustically mediated social interactions. However, regulation of underwater acoustic pollution is currently limited by the scarcity of quantitative data on noise emissions and on the effects of anthropogenic noise on the biological functions of marine fauna (NRC 2005). The present study contributes relevant baseline data to our understanding of some of the potential effects of noise from small boats. The study combines vessel noise quantifications with transmission loss and background noise measurements to build a model for the masking impact on 2 widespread marine mammal species. Results are discussed to contribute readily applicable mitigation measures for areas with high levels of recreational traffic and whale-watching boats.

\section{Masking levels experienced by free-ranging animals}

Free-ranging delphinids in areas with vessel traffic may experience widely varying levels of noise in frequencies used for acoustic communication (e.g. Fig. 1). The population of pilot whales studied here is targeted by an intense year-round whale-watching industry and is thus subject to close approaches by small- and medium-sized boats. The whales tagged here experienced increases in masking noise levels of up to $55 \mathrm{~dB}$ within whistle frequencies over the relatively short duration of the tag attachments. These levels suggest that vessel noise may be an important factor in determining the range of communication signals in this deep-water environment with significant whalewatching and commercial marine traffic activities.

The use of archival acoustic tags to document noise exposures on free-ranging animals is a powerful technique, but has several important limitations. Tag attachment durations on delphinids tend to be short due to their active and social behaviour, which potentially leads to biased samples of the sound field experienced by the animal. On-animal sound recordings also contain many extraneous components, such as noise created when the tag breaks the surface or when water flows past the tag, that do not represent actual noise exposures to the animal. Another dominant component 
in the recordings includes sound generated by the tagged animal. Removing these components from tag recordings to arrive at a measure of the ambient noise level is laborious and introduces some subjectivity. However, the capability to correlate noise exposure with behavioural state and vocalization rates is an important benefit of tag-based studies. Autonomous units recording ambient noise levels continuously in a fixed location, such as EARS (Lammers et al. 2008) or MARUs (Clark et al. 2002), are better suited for quantifying ambient noise variations in a habitat. However, if the sources of noise are not randomly distributed

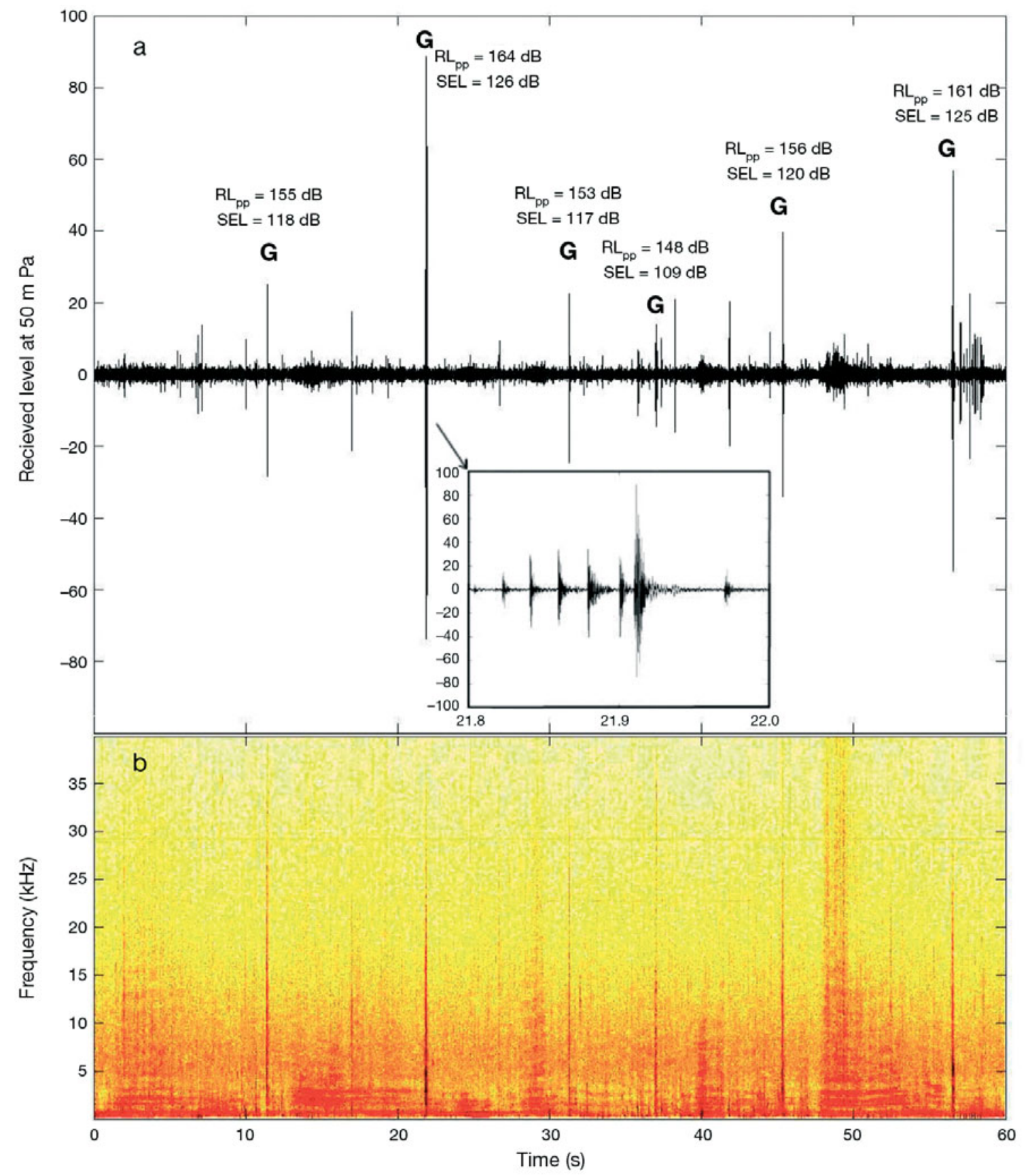

Fig. 5. (a) Received levels recorded at $50 \mathrm{~m}$ from the 4 -stroke vessel during erratic behaviour that included 6 gear shift events (marked $\mathrm{G}$, noted with received peak-peak levels [RL $\mathrm{Rp}_{\mathrm{p}} \mathrm{dB}$ re $1 \mu \mathrm{Pa}$ ] and received sound exposure levels [SEL; $\mathrm{dB}$ re $\left.1 \mu \mathrm{Pa}^{2} \mathrm{~s}^{-1}\right]$ ). Inset: the largest transient has been enlarged to show the reverberant time-domain characteristics of the gear shift. (b) Spectrogram (sample rate: $150 \mathrm{kHz}$; fast Fourier transform [FFT] size: 8192 samples; $50 \%$ overlap) showing the broadband nature of the transients produced by gear shifts 
through the habitat but rather concentrated around cetaceans, as is the case for whale-watch vessels, autonomous recorders will provide measures of ambient noise that do not represent what the animals experience.

One downside of using recordings from archival tags or autonomous acoustic recorders is the difficulty in ascribing changes in noise levels to identified sources in the environment. To better understand how a single source, such as a vessel, affects the ambient noise levels impinging on an animal, it is more robust to measure the noise source properties and model their contribution to a given noise exposure to the animal. In the following, we discuss several parameters required to model the effect of noise on marine mammal communication: (1) measurements of the background noise level experienced by the animal; (2) estimates of the source level of the noise source under representative operating conditions and measurements of sound propagation through the model habitat; and (3) knowledge on how increased sound levels may affect the detection and recognition of acoustic signals used by the animal.

\section{Background noise in shallow and deep water}

The deep-water habitat off the coast of Tenerife was found to be much quieter than the shallow-water habitat of Koombana Bay (Fig. 1). The smaller transmission loss (12.8 dB per logarithmic increase in distance) imposed on continuous noise sources in the shallowwater area implies that vessel noise would propagate further, thus elevating noise levels further from the source. The abundant snapping shrimp in Koombana Bay also contributed to the difference in noise levels.

All background noise measurements in the present study are based on measurement periods restricted to 1 min from each habitat where no recreational vessels or dolphin sounds were evident, so as to prevent such intermittent sound sources from affecting measurements of background noise levels. Ambient noise is known to fluctuate over time (Parks et al. 2009) depending on weather (Knudsen et al. 1948, Richardson et al. 1995), daily, or seasonal variations in biological sounds such as those from snapping shrimp or whales (Everest et al. 1948, Au \& Green 2000) and on changes in anthropogenic activities (Holt et al. 2009). However, the measured background noise levels in the shallowwater environment (Fig. 2) for frequencies $>2$ to $3 \mathrm{kHz}$ were similar to the noise levels recorded in low-speed vessel trials (Fig. 3) measured on different days with similar weather conditions, suggesting that our evaluations of vessel impacts are representative for these conditions.
Vessel noise and transmission loss

The 2 outboard vessels investigated here emitted similar noise levels, with broadband $(0.2$ to $40 \mathrm{kHz})$ and in-band ( 2 to $12.5 \mathrm{kHz}$ ) noise emissions that were primarily determined by vessel speed as found in other studies (Ross 1976, Erbe 2002). Vessel noise suffered close to cylindrical spreading loss when propagating through the shallow-water habitat so that source levels would be overestimated if they were back-calculated from received levels in the present study, using the standard assumption of $20 \log$ (range) spreading loss. Received noise levels were similar at different depths of the water column $(0.5$ to $5.5 \mathrm{~m}$ in a water column of $6 \mathrm{~m}$ depth), meaning that this would not offer delphinids any vertical refuge from increased noise levels in the shallow habitat, except very close to the surface where the pressure release and Lloyd mirror effect (Urick 1983) might reduce noise levels. In contrast, stratification of water layers in a deep-water area causes differences in sound speed, making it likely that noise levels will vary throughout the water column that deep-diving cetaceans, such as pilot whales, utilize. Since sound refraction influences both signals and noise, models that include the relative position of source, receiver and noise sources would be required to uncover the consequences for impact estimates.

Au \& Green (2000) measured noise emissions at speeds of 10 knots from similar vessels with outboard engines. They found back-calculated TOLs between 2 and $6 \mathrm{kHz}$ to be about $160 \mathrm{~dB}$ re $1 \mu \mathrm{Pa}$ at $1 \mathrm{~m}$ assuming spherical spreading loss. This is almost $20 \mathrm{~dB}$ higher than the TOLs in the present study (Fig. 3) corrected for the measured transmission loss of $12.3 \mathrm{~dB}$. Likewise, Williams et al. (2002) estimated much higher source levels of a small vessel for speeds of 3 and 12 knots, while also assuming spherical spreading loss. While it is possible that vessels in these 2 studies were louder than the vessels investigated here, the discrepancy illustrates the importance of measuring transmission loss along with vessel noise emissions when estimating vessel source levels, both to facilitate data comparisons and to subsequently model noise propagation.

\section{Masking impacts}

In-band received noise levels for vessel speeds of 2.5 knots were close to background noise levels and only impacted the communication range at very close range. Our model indicates that vessels moving at an intermediate speed of 5 knots will reduce the communication range of shallow-water dolphins within $50 \mathrm{~m}$ by $26 \%$. A range of $50 \mathrm{~m}$ corresponds to the recom- 
mended minimum distance for vessels near delphinids in many areas (Garrod \& Fennell 2004). Our results support that speed limits $<5$ knots within these distances do indeed reduce the potential masking of communication signals for delphinids, although a potential long-term impact of any low-level masking still cannot be discounted. If vessel speed is increased to 10 knots, cavitation noise increases across a broad spectrum of frequencies (Fig. 3) and impacts acoustic communication at much greater distances (Fig. 4). These reductions in communication range rely on an approximation of $20 \log$ (range) spreading loss for both habitats. In the shallow-water habitat, this approximation may not necessarily be valid since reflections from the surface and bottom will add up with the direct signal during propagation, shifting the transmission loss towards the lower transmission loss found for continuous vessel noise (Urick 1983). If communication signals encountered a transmission loss of $<20 \log$ (range), the actual reduction in communication range for a given increase in noise levels would be decreased.

The variability of cetacean signalling and the sparse information available on their auditory processing introduce some uncertainties in the assessment of noise impacts. To account for species-specific frequency use and auditory processing, we integrated noise in one-third octave bands covering the fundamental frequencies of whistles for the 2 model species. Masking impacts were modelled on the fundamental whistle contour because this has been shown to convey important information between animals (Janik et al. 2006). It is possible that some species put more acoustic energy into the harmonics than in the fundamental contour (Lammers et al. 2003), but it is unknown how information is distributed between the fundamental contour and the harmonics. Our assumption that noise masking narrow band signals is integrated by the auditory system over one-third octave bands roughly corresponds to the critical bandwidths found in bottlenose dolphins (Johnson 1968). Some other toothed whales seem to have quite different auditory bandwidths, especially at higher frequencies (e.g. porpoises; Popov et al. 2006). The implications of narrower auditory filters (higher quality, as quantified by the $Q$ value) would be that the upper (Measure A) and lower (Measure C) impact estimates for the present study (Fig. 4) were moved further apart, increasing the uncertainty as to the potential for masking of communication signals.

Anthropogenic sources have changed ocean ambient noises significantly over the last 50 yr (NRC 2003). The temporal scale of these changes is comparable to only a few life spans of delphinids (60 yr for female pilot whales and 20 to 30 yr for smaller delphinids), meaning that evolutionary adaptations to higher ambient noise levels are unlikely to have occurred. However, temporary changes in signalling may enable animals to cope with different noise levels (Miksis-Olds \& Tyack 2009). Many animal species, including birds (Brumm \& Todt 2002, Slabbekoorn \& Peet 2003) and frogs (Sun \& Narins 2005, Bee \& Swanson 2007), change the frequency content or source level of their sounds to decrease the masking effects of anthropogenic noise whenever possible. Given the importance of acoustic communication for many cetaceans, they will likely also attempt to compensate for increased masking noise by changing the frequency, source level, redundancy, or timing of their signals (Lesage et al. 1999, Foote et al. 2004, Morisaka et al. 2005, Holt et al. 2009). This vocal plasticity is not yet fully understood, and its extent will depend on the ability of the cetacean to change source characteristics as well as the costs associated with such compensations. Changes in frequency use will alter the masking level of background noise and the energy lost to sound absorption. On the other hand, increasing call amplitude or redundancy may be metabolically expensive and requires that communication range is not already maximized. While changes in signal parameters may adequately compensate for small increases in masking noise and are not likely to have any adverse effects during short periods of time, they may not be sufficient to compensate for more severe levels of masking (Wartzok et al. 2003). Measure C provides a lower boundary on the reduction in communication range that might be applicable if the animal shifted its energy to the one-third octave band, where noise levels were least affected by the nearby vessel. However, as in human communication, there are likely multiple layers of information available in the communication signals made by delphinids. Loss of signal intelligibility, as well as accessory cues such as the bearing, behavioural state, or identity of the caller, will be gradual and may occur at much smaller increments in ambient noise than those that would preclude detection of the sound altogether. It is currently unknown whether or how such progressive loss of information transforms animal behaviour or leads to long-term population effects (Brumm \& Slabbekoorn 2005).

\section{Other acoustic vessel impacts}

In addition to broadband masking noise, vessels produce occasional high level transients that could potentially impact cetaceans by causing behavioural disruption at substantial ranges. The high back-calculated gear shift source levels of up to $200 \mathrm{~dB}$ re $1 \mu \mathrm{Pa}_{\mathrm{pp}}$ are not likely to cause temporary threshold shifts in 
toothed whales (Finneran et al. 2000), but could cause behavioural disruption (Richardson et al. 1995). Whale-watching vessels focusing on dolphins may switch gears as often as every $21 \mathrm{~s}$ to maintain their position with respect to the nearby animals (Bejder et al. 2006b). Vessels behaving unpredictably tend to elicit more powerful short-term responses (Williams et al. 2002), and so steps taken to lessen the erratic movement and number of gear shifts of vessels that repeatedly approach wild animals will lessen the impact on these animals.

Since vessels may be audible over much longer distances than expressed by the masking range estimated here, delphinids may potentially react to vessels at much greater distances (Richardson et al. 1995, Erbe 2002). While behavioural reactions may be beneficial to the animals in some respects, by preventing collisions and avoiding areas with high levels of noise, they may also have detrimental effects on the animals by displacing animals from preferred feeding or breeding habitats and by altering their behavioural time budget (Lusseau 2003, Bejder 2005, Lusseau et al. 2009). An additional factor not considered here is that the highfrequency noise generated by cavitation has the potential to impact foraging toothed whales by masking weak echoes from their echolocation signals, which may have a direct bearing on the fitness of the animal (Aguilar Soto et al. 2006). While the noise levels and consequent masking impacts presented in this paper may not necessarily be the most important reason for decreased fitness in delphinids frequented by vessels, they may serve as an overall proxy for negative effects of boat presence around cetaceans and, thus, may be indicative of the potential habitat degradation associated with anthropogenic noise. Conversely, measures taken to reduce the exposure of cetacean populations to vessel noise will reduce the behavioural impact on exposed animals.

\section{Implications and relevance}

The vessels investigated here are representative of typical recreational and coastal research vessels, as well as some smaller whale-watch vessels. Recreational boating is both widespread and increasing in many areas with coastal delphinids (McCarthy 2004) and has been identified as the most important contributor to mid-frequency ambient noise in some coastal habitats (Haviland-Howell et al. 2007, Miksis-Olds et al. 2007). Since many small populations of delphinids are located near shore, it is essential to evaluate the frequency of vessel traffic and the noise contribution from each vessel to estimate the total noise exposure to resident populations.
The whale-watching industry is another important contributor to underwater noise levels in certain cetacean habitats. Vessel noise emissions at a given speed can vary greatly in level and frequency composition depending on vessel, engine and propeller types (Ross 1976). Larger whale-watch vessels with inboard engines may emit comparable or slightly less noise than the outboard boats studied here within the frequency bands of delphinids (Au \& Green 2000). However, cetacean populations in areas with whale-watching are often visited by boats for prolonged periods and may be approached by several boats at once. Single groups of pilot whales in Tenerife may be followed by different whale-watching vessels for hours (Aguilar Soto et al. 2001), while up to 120 boats at a time have been observed following killer whale groups in Canada (Koski 2004). The effects of such heavy whalewatching activity is currently unknown, but even a moderate increase from 1 to 2 tour companies has been shown to have a negative long-term effect on bottlenose dolphin fitness, displacing sensitive individuals and reducing calf recruitment of the remaining individuals (Bejder 2005, Bejder et al. 2006b). Still other habitats show signs of long-term declines in local populations that may also be caused by high-intensity tourism (Lusseau et al. 2006). Results presented here corroborate the guidelines for sustainable dolphinwatching that some areas already utilize (Garrod \& Fennell 2004) by showing that masking impacts from single vessels are minimized by maintaining speeds $<5$ knots and keeping $>50 \mathrm{~m}$ distance between animals and vessels. Unfortunately, our study cannot address the cumulative effects of multiple whale-watch vessels overlapping with each other, nor can it account for vessels with unusual noise emissions or that approach whales inadvertently. Further studies that investigate the prevalence and severity of masking noise levels under natural conditions, by measuring or estimating the noise budget of free-ranging toothed whales, will improve our understanding of the acoustic consequences of focused whale-watch activities.

Finally, close focal follow techniques are often used by scientists studying free-ranging cetaceans. Since small motorized vessels are often used for these studies, the nearby animals may encounter similar masking effects to those quantified here. Following an animal at a distance and at slow speeds of 2.5 knots will cause little masking of delphinid communication, but following a dolphin at close range for a long time and at greater speeds could significantly impede acoustic contact between the focal individual and conspecifics, in addition to any effects of stress from the persistent boat presence to which the animal may be subjected. Thus, our data suggest that the behaviour and noise profiles of research vessels may be a source of potential bias in 
studies of free-ranging delphinids and should be considered when designing field experiments (Bejder \& Samuels 2003).

\section{CONCLUSION AND RECOMMENDATIONS}

In the present study, we have taken a biophysical approach to address an important parameter of habitat quality for cetaceans: acoustic pollution. Masking levels, quantified as a decrease of in-band SNR, were measured to assess the relative impact of noise from small vessels on the communication range of free-ranging delphinids. For small vessels with outboard engines, we found that speeds $>5$ knots and approach distances closer than some $50 \mathrm{~m}$ to delphinids will significantly reduce their acoustic communication range. Although the level of impact will depend on the species in question, the behavioural state and the habitat, vessel guidelines that recommend low speeds, keeping a minimum distance of $>50 \mathrm{~m}$ and employing few if any gear shifts will reduce noise impacts on delphinids in general and minimize the effects of masking on communication in particular. Finally, the noise emissions of a vessel will depend on ship, engine and propeller design and should be measured before drawing conclusions about the impact on cetaceans. Modern vessel-quieting techniques that reduce the inband noise emissions (specifically cavitation noise) of a vessel by as little as $6 \mathrm{~dB}$ (halving the radiated acoustic pressure) will reduce the water volume around the vessel at which a cetacean will experience a given masking effect by 4 - to 8-fold, depending on propagation conditions. We conclude that implementation of vessel-quieting techniques and noise standards along with whalewatching guidelines for boat behaviour and distance would significantly reduce many of the potentially negative effects of whale-watching and boating activities.

Acknowledgements. This work was supported by the PhD School of Aquatic Sciences (SOAS), Aarhus University, DK, WWF Verdensnaturfonden and Aase \& Ejnar Danielsens Foundation, the Siemens Foundation, a research agreement between La Laguna University and Woods Hole Oceanographic Institution, the Faculty of Science at the University of Aarhus, Denmark, and the Danish Natural Science Foundation via a Steno scholarship and frame grants to P.T.M. M.J. and N.A. were funded by the National Oceanographic Partnership Program. We thank M. Hansen, M. Wilson, $H$. Schack, H. Smith, S. Allen, J. Knust, F. Díaz, I. Domínguez, C. Aparicio, A. Hernández, C. Gonzalez and P. Aspas for assistance in the field, as well as Murdoch University Naturaliste Charters, and the Dolphin Discovery Center in Bunbury for logistics support. Research in the Canary Islands was performed under a permit from the Canary Islands Government granted to La Laguna University, whereas research in Australia was conducted under a permit to L.B. from the Department of Environment and Conservation and Ethics Approval from Murdoch University.

\section{LITERATURE CITED}

Aguilar Soto N (2006) Acoustic and diving behaviour of pilot whales (Globicephala macrorhynchus) and Blainville's beaked whales (Mesoplodon densirostris) off the Canary Islands, with implications for effects of man-made noise and ship strikes. PhD thesis, La Laguna University, Tenerife

Aguilar Soto N, Díaz F, Carrillo M, Brito A and others (2001) Evidence of disturbance of protected cetacean populations in the Canary Islands. SC/53/WW1. IWC, London

Aguilar Soto N, Johnson M, Madsen PT, Tyack PL, Bocconcelli A, Borsani JF (2006) Does intense ship noise disrupt foraging in deep-diving Cuvier's beaked whales (Ziphius cavirostris)? Mar Mamm Sci 22:690-699

Arveson PT, Vendittis DJ (2000) Radiated noise characteristics of a modern cargo ship. J Acoust Soc Am 107:118-129

Au WWL (1993) The sonar of dolphins. Springer Verlag, New York

Au WWL, Green M (2000) Acoustic interaction of humpback whales and whale-watching boats. Mar Environ Res 49: 469-481

Au WWL, Moore PWB (1984) Receiving beam patterns and directivity indices of the Atlantic bottlenose dolphin Tursiops truncatus. J Acoust Soc Am 75(1):255-262

Beale CM, Monaghan P (2004) Behavioural responses to human disturbance: A matter of choice? Anim Behav 68: 1065-1069

Bee MA, Swanson EM (2007) Auditory masking of anuran advertisement calls by road traffic noise. Anim Behav 74: 1765-1776

Bejder L (2005) Linking short and long-term effects of naturebased tourism on cetaceans. PhD thesis, Dalhousie University, Halifax

Bejder L, Samuels A (2003) Evaluating the effects of naturebased tourism on cetaceans. In: Gates N, Hindell $M$, Kirkwood R (eds) Marine mammals: fisheries, tourism \& management issues. CSIRO Publishing, Collingwood, Australia, p 229-256

> Bejder L, Samuels A, Whitehead H, Gales N (2006a) Interpreting short-term behavioural responses to disturbance within a longitudinal perspective. Anim Behav 72:1149-1158

Bejder L, Samuels A, Whitehead H, Gales N and others (2006b) Decline in relative abundance of bottlenose dolphins exposed to long-term disturbance. Conserv Biol 20: 1791-1798

Brumm H, Slabbekoorn H (2005) Acoustic communication in noise. Adv Stud Behav 35:151-209

Brumm H, Todt D (2002) Noise-dependent song amplitude regulation in a territorial songbird. Anim Behav 63: 891-897

Buckstaff KC (2004) Effects of watercraft noise on the acoustic behaviour of bottlenose dolphins, Tursiops truncatus, in Sarasota Bay, Florida. Mar Mamm Sci 20:709-725

Caldwell MC, Caldwell DK (1969) Simultaneous but different narrow-band sound emissions by a captive eastern Pacific pilot whale, Globicephala scammoni. Mammalia 33: 505-508

Clark CW, Borsani JF, Notarbartolo di Sciara G (2002) Vocal activity of fin whales, Balaenoptera physalus, in the Ligurian Sea. Mar Mamm Sci 18:286-295

Connor RC, Wells RS, Mann J, Read AJ (2000) The bottlenose dolphin. In: Mann J, Connor RC, Tyack P, Whitehead H (eds) Cetacean societies: field studies of whales and dolphins. University of Chicago Press, Chicago, IL

Connor RC, Smolker R, Bejder L (2006) Synchrony, social behaviour and alliance affiliation in Indian Ocean bottlenose dolphins, Tursiops aduncus. Anim Behav 72: 
$1371-1378$

Deecke VB, Ford JKB, Slater PJB (2005) The vocal behaviour of mammal-eating killer whales: communicating with costly calls. Anim Behav 69:395-405

Erbe C (2002) Underwater noise of whale-watching boats and potential effects on killer whales (Orcinus orca), based on an acoustic impact model. Mar Mamm Sci 18:394-418

Everest FA, Young RW, Johnson MW (1948) Acoustical characteristics of noise produced by snapping shrimp. J Acoust Soc Am 20:137-142

Fay RR (1988) Hearing in vertebrates: a psychophysics databook. Hill-Fay Associates, Winnetka, IL

Finneran JJ, Schlundt CE, Carder DA, Clark JA, Young JA, Gaspin JB, Ridgway SH (2000) Auditory and behavioral responses of bottlenose dolphins (Tursiops truncatus) and a beluga whale (Delphinapterus leucas) to impulsive sounds resembling distant signatures of underwater explosions. J Acoust Soc Am 108:417-431

Foote AD, Osborne RW, Hoelzel AR (2004) Whale-call response to masking boat noise. Nature 428:910

$>$ Garrod B, Fennell DA (2004) An analysis of whalewatching codes of conduct. Ann Tourism Res 31:334-352

Gelfand SA (2004) Hearing - an introduction to psychological and physiological acoustics. Marcel Dekker, New York

Gerhardt HC, Klump GM (1988) Masking of acoustic-signals by the chorus background-noise in the green tree froga limitation on mate choice. Anim Behav 36:1247-1249

Haviland-Howell G, Frankel AS, Powell CM, Bocconcelli A, Herman RL, Sayigh LS (2007) Recreational boating traffic: a chronic source of anthropogenic noise in the Wilmington, North Carolina Intracoastal Waterway. J Acoust Soc Am 122:151-160

Heimlich-Boran JR (1993) Social organisation of the short finned pilot-whale, with special reference to the comparative social ecology of delphinids. PhD thesis, University of Cambridge, Cambridge

Heimlich-Boran JR, Heimlich-Boran S (1990) Occurrence and group structure of short-finned pilot whales Globicephala macrorhynchus off the western coast of Tenerife, Canary Islands. Eur Res Cetaceans 4:102-104

Heimlich-Boran JR, Heimlich-Boran S (1992) Social structure of short-finned pilot whales Globicephala macrorhynchus off Tenerife, Canary Islands. Eur Res Cetaceans 6:154-157

Holt MM, Noren DP, Veirs V, Emmons CK, Veirs S (2009) Speaking up: killer whales (Orcinus orca) increase their call amplitude in response to vessel noise. J Acoust Soc Am 125:EL27-EL32

Hoyt E (1993) Saving whales by watching them. New Sci 138: $45-46$

IWC (International Whaling Commission) (2006) Report of the scientific committee. J Cetacean Res Manag 8(Suppl): $1-65$

Janik VM (2000) Food-related bray calls in wild bottlenose dolphins (Tursiops truncatus). Proc R Soc Lond B Biol Sci 267:923-927

Janik VM (2005) Underwater acoustic communication networks in marine mammals. In: McGregor PK (ed) Animal communication networks. Cambridge University Press, Cambridge

Janik VM, Slater PJ (1998) Context-specific use suggests that bottlenose dolphin signature whistles are cohesion calls. Anim Behav 56:829-838

Janik VM, Sayigh LS, Wells RS (2006) Signature whistle shape conveys identity information to bottlenose dolphins. Proc Natl Acad Sci USA 103:8293-8297

Johnson SC (1967) Sound detection thresholds in marine mammals. In: Tavolga WN (ed) Marine bio-acoustics.
Pergamon, New York

Johnson CS (1968) Masked tonal thresholds in bottlenosed porpoise. J Acoust Soc Am 44:965-967

$>$ Johnson MP, Tyack PL (2003) A digital acoustic recording tag for measuring the response of wild marine mammals to sound. IEEE J Oceanic Eng 28:3-12

Knudsen VO, Alford RS, Emling JW (1948) Underwater ambient noise. J Mar Res 7:410-429

Koski K (2004) The soundwatch boater education program: trends in vessel traffic with southern resident killer whales. The Whale Museum, Friday Harbor, WA

Lammers MO, Au WWL, Herzing DL (2003) The broadband social acoustic signaling behavior of spinner and spotted dolphins. J Acoust Soc Am 114:1629-1639

Lammers MO, Brainard RE, Au WWL, Mooney TA, Wong KB (2008) An ecological acoustic recorder (EAR) for long-term monitoring of biological and anthropogenic sounds on coral reefs and other marine habitats. J Acoust Soc Am 123:1720-1728

> Lesage V, Barrette C, Kingsley MCS, Sjare B (1999) The effect of vessel noise on the vocal behavior of belugas in the St. Lawrence River estuary, Canada. Mar Mamm Sci 15: $65-84$

Lohr B, Wright TF, Dooling RJ (2003) Detection and discrimination of natural calls in masking noise by birds: estimating the active space of a signal. Anim Behav 65:763-777

> Lusseau D (2003) Effects of tour boats on the behavior of bottlenose dolphins: using Markov chains to model anthropogenic impacts. Conserv Biol 17:1785-1793

Lusseau D, Slooten L, Currey RJC (2006) Unsustainable dolphin-watching tourism in Fiordland, New Zealand. Tourism Mar Environ 3:173-178

Lusseau D, Bain DE, Williams R, Smith JC (2009) Vessel traffic disrupts the foraging behavior of southern resident killer whales Orcinus orca. Endang Species Res 6:211-221

> Madsen PT, Wahlberg M, Tougaard J, Lucke K, Tyack P (2006) Wind turbine underwater noise and marine mammals: implications of current knowledge and data needs. Mar Ecol Prog Ser 309:279-295

> Marten K, Marler P (1977) Sound transmission and its significance for animal vocalization. Behav Ecol Sociobiol 2: $271-290$

McCarthy E (2004) International regulation of underwater sound: establishing rules and standards to address ocean noise pollution. Kluwer Academic Publishers, Boston, MA

Miksis-Olds JL, Miller JH (2006) Transmission loss in manatee habitats. J Acoust Soc Am 120:2320-2327

Miksis-Olds JL, Donaghay PL, Miller JH, Tyack PL, Nystuen JA (2007) Noise level correlates with manatee use of foraging habitats. J Acoust Soc Am 121:3011-3020

Miksis-Olds JL, Tyack PL (2009) Manatee (Trichechus manatus) vocolization usage in relation to environmental noise levels. J Acoust Soc Am 125:1806-1815

Møhl B (1981) Masking effects of noise: their distribution in time and space. Arctic Pilot Project, Calgary, AB

Montgomery JC, Jeffs A, Simpson SD, Meekan M, Tindle C (2006) Sound as an orientation cue for the pelagic larvae of reef fishes and decapod crustaceans. Adv Mar Biol 51: 143-196

Morisaka T, Shinohara M, Nakahara F, Akamatsu T (2005) Effects of ambient noise on the whistles of Indo-Pacific bottlenose dolphin populations. J Mammal 86:541-546

Nowacek SM, Wells RS, Solow AR (2001) Short-term effects of boat traffic on bottlenose dolphins, Tursiops truncatus, in Sarasota Bay, Florida. Mar Mammal Sci 17:673-688

> Nowacek DP, Thorne LH, Johnston DW, Tyack PL (2007) Responses of cetaceans to anthropogenic noise. Mammal 
Rev 37:81-115

NRC (National Research Council) (1994) Low-frequency sound and marine mammals: current knowledge and research needs. National Academy Press, Washington, DC

NRC (National Research Council) (2003) Ocean noise and marine mammals. National Academy Press, Washington, DC

NRC (National Research Council) (2005) Marine mammal populations and ocean noise: determining when noise causes biologically significant effects. National Academy Press, Washington, DC

O'Connor S, Campbell R, Cortez H, Knowles T (2009) Whale Watching Worldwide: tourism numbers, expenditures and expanding economic benefits. International Fund for Animal Welfare, Yarmouth, MA

Parks SE, Urazghildiiev I, Clark CW (2009) Variability in ambient noise levels and call parameters of North Atlantic right whales in three habitat areas. J Acoust Soc Am 125: 1230-1239

Popov VV, Supin AY, Wang D, Wang KX (2006) Nonconstant quality of auditory filters in the porpoises, Phocoena phocoena and Neophocaena phocaenoides (Cetacea, Phocoenidae). J Acoust Soc Am 119:3173-3180

Popper A (2003) The effects of anthropogenic sounds on fishes. Fisheries (Bethesda) 28:24-31

Rendell LE, Matthews JN, Gill A, Gordon JCD, Macdonald DW (1999) Quantitative analysis of tonal calls from five odontocete species, examining interspecific and intraspecific variation. J Zool (Lond) 249:403-410

Renouf D (1984) The vocalization of the harbor seal pup (Phoca vitulina) and its role in the maintenance of contact with the mother. J Zool 202:583-590

Richardson WJ, Greene CRJ, Malme CI, Thomson DH (1995) Marine mammals and noise. Academic Press, London

Ross D (1976) Mechanics of underwater noise. Pergamon Press, New York

Slabbekoorn H, Peet M (2003) Birds sing at a higher pitch in urban noise. Nature 424:267

Submitted: June 16, 2008; Accepted: July 7, 2009
Smolker RA, Mann J, Smuts BB (1993) Use of signature whistles during separations and reunions by wild bottlenose dolphin mothers and infants. Behav Ecol Sociobiol 33: 393-402

Southall BL (2005) Final report of the International Symposium 'Shipping noise and marine mammals: a forum for science, management, and technology'. NOAA Fisheries Acoustics Program, Arlington, VA. Available at: www. nmfs.noaa.gov/pr/acoustics/shipnoise.htm

Stillman RA, Goss-Custard JD (2002) Seasonal changes in the response of oystercatchers Haematopus ostralegus to human disturbance. J Avian Biol 33:358-365

Sun JWC, Narins PM (2005) Anthropogenic sounds differentially affect amphibian call rate. Biol Conserv 121:419-427

Tyack PL (2008) Implications for marine mammals of largescale changes in the marine acoustic environment. J Mammal 89:549-558

Tyack PL, Miller EH (2002) Vocal anatomy, acoustic communication and echolocation. In: Hoelzel AR (ed) Marine mammal biology. Blackwell Science., Oxford, p 142-184

Urick RJ (1983) Principles of underwater sound. Peninsula, Los Altos, CA

> Wartzok D, Popper AN, Gordon JCD, Merrill J (2003) Factors affecting the responses of marine mammals to acoustic disturbance. Mar Technol Soc J 37:6-15

Watwood SL, Owen ECG, Tyack PL, Wells RS (2005) Signature whistle use by temporarily restrained and free-swimming bottlenose dolphins, Tursiops truncatus. Anim Behav 69:1373-1386

Weilgart L (2007) The impacts of anthropogenic ocean noise on cetaceans and implications for management. Can J Zool 85:1091-1116

Williams R, Bain DE, Ford JKB, Trites AW (2002) Behavioural responses of male killer whales to a 'leapfrogging' vessel. J Cetacean Res Manag 4:305-310

> Wursig B, Wursig M (1977) Photographic determination of group-size, composition, and stability of coastal porpoises (Tursiops truncatus). Science 198:755-756

Proofs received from author(s): September 7, 2009 